\title{
Review
}

\section{Sing the rage: Listening to anger after mass violence}

\author{
Sonali Chakravarti \\ Chicago University Press, Chicago, 2014, 232 pp., \$35.00, ISBN: 978-0226119984 \\ Contemporary Political Theory (2015) 14, e31-e34. doi:10.1057/cpt.2014.46; \\ published online 28 October 2014
}

Anger has had a bad reputation among students of post-conflict justice. Its disruptiveness, its capacity to wreak havoc and to push societies into a spiral of violence are some of the reasons invoked against a political confrontation with anger. Sonali Chakravarti joins the growing number of voices who defend anger and make an attempt to recuperate its political significance for processes of dealing with a past of violence.

The book analyses victims' testimonies given in front of the South African Truth and Reconciliation Commission (TRC, 1996-1998) and, based on a close reading thereof, proposes three dimensions of anger that are relevant for traumatised societies: cognitive, confrontational and kinetic. Cognitively, anger gives the audience information about the speaker's needs, interests and fears, and requires that recognition be given to her status as an agent with dignity. Anger by the formerly excluded is politically very important in terms of what it tells us about the boundaries of the demos. Confrontationally, anger can target the limits of what is possible in terms of repair or punishment. It can appear to be disproportionate, extreme or erroneous, and its value consists not in what it tells us about justice, but in revealing the deep effects of the experience of violence on the person. Last but not least, the kinetic value of anger refers to the energy that anger can infuse political life with, irrespective of the cause to which it is attached. In the author's own words, '[T]he particular tone, modulation and cadence of an individual's voice are highly idiosyncratic and can betray the speaker's fears and scepticism even when the words she uses suggest otherwise' (p. 152).

In order to valorise these three dimensions of anger for the future of the political community, the book recommends the cultivation of an ethics of listening: listening promotes inclusion and enables witnesses to become citizens who can build trusting relations within a safe public sphere. Instead of a visual model of looking at emotions from a distance, listening and responding are proposed as more productive practices in the wake of violence.

(C) 2015 Macmillan Publishers Ltd. 1470-8914 Contemporary Political Theory Vol. 14, 3, e31-e34 www.palgrave-journals.com/cpt/ 
The argument is positioned in contradistinction to two sceptical accounts of emotion. First, Adam Smith's model, having at its centre the impartial spectator, is found to be too dismissive of emotion in its messiness. In making merit and propriety conditions for the validity of emotional expressions, Smith unduly restricts the type of emotions worth paying heed to. Thus, he cannot provide a useful framework for understanding the complex emotional circumstances of the TRC. Second, Hannah Arendt's account of politics - and of the role of speech and narratives therein - could be productive for theorising the political value of testimony in the TRC, especially in terms of their capacity to bring novelty in the world that witnesses share with others. However, Arendt's requirement that emotion undergo 'translation' before it is allowed out of the private sphere and into the public sphere, as well as her worries that emotions distract citizens from politics, make Arendt an unlikely supporter of the TRC. The analysis of these two thinkers' work on emotion is very interesting, careful and insightful. However, it remains unclear why, given the overall purpose of the book, the author chose to discuss them to such great lengths. While the question of theoretical delimitation is important, the reader is left wondering why so much space is dedicated to the detailed analysis of theoretical frameworks that are ultimately not used to meaningfully prop up the overall argument.

The merits of the book are many. It brings valuable insights into the various functions of anger expressed in moments of radical transformation and adds an important contribution to the growing scholarship trying to redeem emotion for politics. The main original argument proposed here is that the strong connection between anger and justice is not the only reason why we should care about - and listen carefully to - this often-maligned emotion. The shift from a visual to an aural model of politics is also theoretically interesting, as it has the potential to add new ideas about the kind of ethos polities need to cultivate in the aftermath of conflict - and not only then. The discussion of the value and emotional risks associated with the development of trust is yet another reason why this book constitutes a theoretical reference point for scholars of transitional justice. Last but not least, the connection between the Eichmann trial and the TRC is provocative and historically interesting, even if contentious. In what follows, I will highlight two areas of theorising that I think are problematic: the conceptualisation of the faces of anger and the account of the ethics of listening.

Regarding the faces of anger, the author persuasively argues that we should care about anger even when it is not connected to justice: when it expresses needs and fears that are unreasonable and contradictory, and when it infuses our political world with energy. These aspects of anger, thinks Chakravarti, should make us doubt the merits of the cognitive account of emotion. Yet it is unclear why the author thinks the confrontational and the kinetic dimensions of anger highlight the limits of the cognitive model.

The book seems to unduly moralise the cognitive model of emotion by presupposing that the judgment cognitivists conceptualise as constitutive of emotion 
is a necessarily moral - justice-related - judgment. In other words, righteous anger is thought to be the only kind of anger cognitivists can accommodate. This is a rather narrow reading of the cognitivist theory of emotion. Solomon (1988) himself - the target of Chakravarti's criticism - offers a very broad understanding of the objects of judgment in emotion: our own selves, our place in the world, our ideals, structures and mythologies give content to emotion.

Moreover, affirming that judgments are part of emotion does not imply that these judgments are reasonable, non-contradictory, moderate, coherent or communicable. The 'confrontational' forms of anger - anger that communicates frustration about the justice process and one's own role in it, about intangible and invisible consequences of violence, or anger whose causes are not easily identifiable - are perfectly at home in the cognitivist paradigm: they are intelligible as the expression of an agent's evaluation of the world and her own and others' role in it. Cognitivists do not think judgment plays the same role in rational enquiry and in emotion, nor do they think the same standards of evaluation apply to both. I would like to suggest that what is interesting about Chakravarti's confrontational anger is that it challenges the audience - and especially power-holders - with questions about the necessarily imperfect nature of justice in the wake of often-intractable forms of harm. Confrontational anger is also important because it requires special efforts on the part of the listener/respondent, and the examples the author gives - testimonies by Jean Améry, Notrose Nobomvu Konile, Nomakula Evelyn Zweni - attest to this particular aspect (pp. 143-149).

My last point about anger concerns its kinetic energy. To cite Solomon (1988), '(T)he aim of a cognitive theory of emotions is not to reduce the drama of emotion to cool, calm belief but to break down the insidious distinctions that render emotions stupid and degrading and eviscerate cognition' (p. 190). In other words, to say that emotion has a cognitive component does not mean that this is all there is to emotion. Cognitivists account for the physiological dimensions of emotion, for its expressive force and its action-orientedness. Including thought, belief, judgment among the components of emotions does not translate into an unnecessary intellectualisation of affect.

Regarding listening as a practice of engaging anger productively, I would like to suggest that it merits further discussion. It would be important to explain why it is that the ears - rather than the eyes - have a better chance at capturing the various forms of anger. In other words, it would be important to explain why this is more than a change of metaphor. One could argue that the problem with Smith's account - in the way Chakravarti presents it - is not that it is visual, but that it imposes a number of conditions on the kind of emotions can be 'seen' and from where. What is interesting about the listening perspective is the burden it places on the listener in terms of her effort to make sense and deal with others' anger. Unpacking these burdens and explaining how habits of listening could be cultivated in order to support a revised account of politics - one that valorises the lessons from Arendt and Smith while avoiding their shortcomings - would further develop the argument. 
To conclude, Sing the Rage opens up an important space for thinking about emotions in the wake of conflict. Though sometimes theoretically imprecise, it successfully casts doubt over widely held assumptions about the public role of negative emotions. Last but not least, the book creatively crosses unnecessarily rigid disciplinary boundaries between political science, ethnography and political philosophy.

\section{Reference}

Solomon, R.C. (1988) On emotions as judgements. American Philosophical Quarterly 25(2): 183-191.

Mihaela Mihai

University of York, York YO10 5DD, UK

e34 (C) 2015 Macmillan Publishers Ltd. 1470-8914 Contemporary Political Theory Vol. 14, 3, e31-e34 